\title{
Influence of two different GH dosage regimens on final height, bone geometry and bone strength in GH-deficient children
}

\author{
Giorgio Radetti, Gianluca D’Addato, Davide Gatti ${ }^{2}$, Mauro Bozzola ${ }^{1}$ and Silvano Adami ${ }^{2}$ \\ Department of Paediatrics, Regional Hospital of Bolzano, via L Boehler 5, 39100 Bolzano, Italy, ${ }^{1}$ Department of Paediatrics, University of Pavia, Pavia, \\ Italy and ${ }^{2}$ Rheumatologic Department, Hospital of Valeggio (VR), Verona, Italy
}

(Correspondence should be addressed to G Radetti; Email: giorgio.radetti@asbz.it)

\begin{abstract}
Objective: The aim was to investigate the effects of two different GH dosage regimens on growth, bone geometry and bone strength.

Subjects and methods: Final height; parentally adjusted final height; the metacarpal index (MI) SDS, the inner and outer diameters; and the total cross-sectional area (CSA), cortical CSA, medullary CSA and bone strength (Bending Breaking Resistance Index (BBRI)) were evaluated at the metacarpal site in two cohorts of GH-deficient children, treated with two different doses of GH. Group 1 ( 38 patients) was treated with $0.16 \mathrm{mg} / \mathrm{kg}$ body weight per week of $\mathrm{GH}$ and group 2 (37 patients) with $0.3 \mathrm{mg} / \mathrm{kg}$ per week.

Results: At the end of treatment, with group 1 vs group 2, height SDS was $-0.84 \pm 1.07$ vs $-0.46 \pm 0.76$, and parentally adjusted height SDS was $0.14 \pm 1.08$ vs $0.27 \pm 0.82$. Parentally adjusted relative height gain was $1.14 \pm 0.89$ vs $2.14 \pm 0.72$ SDS $(P<0.0001)$. MI SDS was $0.58 \pm 1.31$ vs $-0.42 \pm 1.54(P<0.005)$. MI SDS gain was $0.07 \pm 1.41$ vs $-0.35 \pm 1.85$. There was no difference between groups in the outer and inner diameter, in the total and cortical CSAs, whereas medullary CSA was higher in group $2(P<0.05)$. BBRI was $10.02 \pm 5.37$ vs $11.52 \pm 5.49 \mathrm{~cm}^{3}$, and BBRI gain was $3.33 \pm 5.06$ vs $6.88 \pm 6.65(P=0.01) . P$ values were assessed using student's $t$-test.

Conclusion: Higher GH doses result in a greater height gain and improved bone strength.
\end{abstract}

European Journal of Endocrinology 154 479-482

\section{Introduction}

Growth hormone $(\mathrm{GH})$ promotes longitudinal growth by stimulating the epiphyseal growth plates of the long bones (1). It acts mainly on the resting zone chondrocytes and is responsible for local insulin-like growth factor (IGF)-I production, which stimulates clonal expansion of proliferating chondrocytes in an autocrine/paracrine manner (2). GH stimulates bone growth in length and diameter, enhancing the accrual of trabecular (3) and cortical bone (4) up to the attainment of peak bone mass in young adulthood (5).

We have previously shown that final height in GHdeficient (GHD) patients is dosage dependent (6). We therefore wondered whether a different $\mathrm{GH}$ dosage could also influence the geometry of the long bones. In fact, both GH and IGF-I stimulate the cortical bone directly $(7,8)$, as well as indirectly, by increasing the muscle strength and thus the bone load $(9,10)$. The aim of this study was thus to verify whether a different GH dosage, in addition to its effect on final height, would also influence the bone geometry and the bone strength of the metacarpal bone in two groups of GHD children.

\section{Subjects and methods}

Seventy-five children $(48 \mathrm{M}, 27 \mathrm{~F})$ with isolated idiopathic GH deficiency were selected for the study. The diagnosis of GH deficiency was based on the following criteria: height of $<2$ SDS and/or height velocity of $<10$ th centile for chronologic age when measured for more than 6 months; bone age delay of $>2$ years compared with chronologic age and $\mathrm{GH}$ peak of $<10 \mu \mathrm{g} / \mathrm{l}$ after at least two consecutive conventional pharmacologic tests. All children had a normal hypophysis on magnetic resonance imaging (MRI), and were not affected by any cardiovascular, respiratory, renal or rheumatic diseases, or by any other endocrine disorders.

Thirty-eight children (25M, 13F) were treated in Pavia with a weekly recombinant $\mathrm{GH}$ dosage of $0.16 \mathrm{mg} / \mathrm{kg}$ for 
a mean period of $4.9 \pm 2.5$ years (group 1 ), while the other $37(23 \mathrm{M}, 14 \mathrm{~F})$ were treated in Bolzano with a weekly recombinant $\mathrm{GH}$ dosage of $0.3 \mathrm{mg} / \mathrm{kg}$ for a mean period of $3.9 \pm 1.5$ years (group 2 ). The auxologic features of the patients are reported in Table 1 . They were all regularly followed up every 6 months until final height. GH treatment was discontinued at a bone age of $>15$ years in girls and $>17$ years in boys. Height was measured in both centers with a wall-mounted Harpenden stadiometer by the same trained personnel and reported as height SDS for chronologic age according to Tanner and Whitehouse (11). Moreover, in order to compare also the patient's genetic potential for growth, we calculated the parentally adjusted height SDS, that is, the difference between height SDS for chronologic age and target height SDS (average height of both parents plus $6.55 \mathrm{~cm}$ for boys and minus $6.55 \mathrm{~cm}$ for girls). The difference between the parentally adjusted height SDS on attainment of adult stature and that before starting treatment was defined as relative height gain. The body-mass index (weight $(\mathrm{kg}) /$ height $^{2}\left(\mathrm{~m}^{2}\right)$ ) SDS was calculated according to Rolland-Cachera et al. (12). Radiographs of the left hand and wrist, taken before starting GH treatment and at final height, were used to assess bone age by the method of Greulich and Pyle (13) and also to evaluate metacarpal bone geometry. We determined firstly the metacarpal index (MI), which is a relative measure of the thickness of the 2 nd metacarpal cortical bone, taken at its narrowest site, as previously described (14). The values were then converted to standard deviation score (MI SDS) according to our normative data (14). We also evaluated the inner and outer diameter at the same site and calculated the total, cortical and endomedullary cross-sectional area (CSA). The MI SDS of the GHD children was also compared with that observed in a group of 44 obese children (mean chronologic age 10.9 \pm 2.7 , bone age $12.2 \pm 2.9$ years, height SDS $1.25 \pm 1.1$ and BMI SDS $6.24 \pm 1.6)$ and with that one of another group of 10 children with tall stature, mean chronologic age 13.8 \pm 2.0 years, bone age $14.8 \pm 2.3$ years, height SDS $2.76 \pm 0.76$ and BMI SDS 0.26 \pm 1.08 .

The bone strength of the metacarpus depends upon its material property (which cannot be directly

Table 1 Baseline and final characteristics of the $75 \mathrm{GHD}$ children.

\begin{tabular}{lcc}
\hline & Group 1 & Group 2 \\
\hline No. of subjects & 38 & 37 \\
Chronologic age (years) & $10.7 \pm 3.1$ & $11.7 \pm 2.4$ \\
Bone age (years) & $9.2 \pm 2.7$ & $10.1 \pm 2.4$ \\
Height SDS & $-1.41 \pm 0.68$ & $-2.47 \pm 0.83^{*}$ \\
BMl SDS & $0.02 \pm 1.35$ & $0.68 \pm 2.21$ \\
TH & $-1.11 \pm 0.81$ & $-0.69 \pm 0.66$ \\
FH SDS & $-0.84 \pm 1.07$ & $-0.46 \pm 0.76$ \\
\hline
\end{tabular}

$\mathrm{TH}$ : target height; $\mathrm{FH}$ : final height.

${ }^{*} P<0.05$. measured in vivo) and the so-called cross-sectional moment of inertia (15), which is a function of the fourth power of the cortical ring. By assuming a constant material property, the Bending Breaking Resistance Index (BBRI) can be calculated as follows: outer diameter (D) to the fourth power minus inner diameter (d) to the fourth power divided by D.

\section{Statistical analysis}

The data were normally distributed and are reported as mean \pm S.D. Student's paired and unpaired $t$-tests were used to verify differences within and between groups. One-way analysis of variance (ANOVA) was also used to check differences in the MI between GHD, obese and tall children. A $P$ value of less than 0.05 was considered statistically significant. The statistical program Statgraphics V5.1 (Magnugistics, Rockville, MD, USA) was employed.

\section{Results}

\section{Auxology}

Before treatment, group 1 showed a greater height SDS (Table 1$)(P<0.0001)$ and parentally adjusted height SDS than group 2 (Table 2$)(P<0.0001)$. However, at the end of treatment, at a mean age of $15.8 \pm 1.6$ and $16.9 \pm 1.7$ years respectively, no difference in height SDS (Table 1) and parentally adjusted height SDS (Table 2) was seen. The catch-up growth in group 2 is well accounted for by the relative greater height gain observed in this group (Table 2) $(P<0.0001)$. BMI SDS was similar in the two groups at final height $(0.35 \pm 1.2$ vs $0.63 \pm 1.53)$.

\section{Bone geometry}

MI SDS was greater in group 1 before treatment $(P<0.05)$ as well as at final height (Table 3) $(P<0.005)$. There was, however, no difference in the

Table 2 Parentally adjusted height SDS and relative height gains.

\begin{tabular}{lcccc}
\hline & $\boldsymbol{n}$ & Baseline & Adult & Relative gain \\
\hline Group 1 & 38 & $-1.0 \pm 0.95$ & $0.14 \pm 1.08$ & $1.14 \pm 0.89$ \\
Group 2 & 37 & $-1.87 \pm 0.86^{*}$ & $0.27 \pm 0.82$ & $2.14 \pm 0.72^{*}$ \\
\hline
\end{tabular}

Table 3 Metacarpal index SDS at baseline and at final height.

\begin{tabular}{lcccr}
\hline & $\boldsymbol{n}$ & Baseline & Adult & Relative gain \\
\hline Group 1 & 38 & $0.51 \pm 0.99$ & $0.58 \pm 1.31$ & $0.07 \pm 1.41$ \\
Group 2 & 37 & $-0.02 \pm 1.16^{*}$ & $-0.42 \pm 1.54^{\star *}$ & $-0.35 \pm 1.85$ \\
\hline
\end{tabular}

${ }^{\star} P<0.05 ;{ }^{*} P<0.005$ 


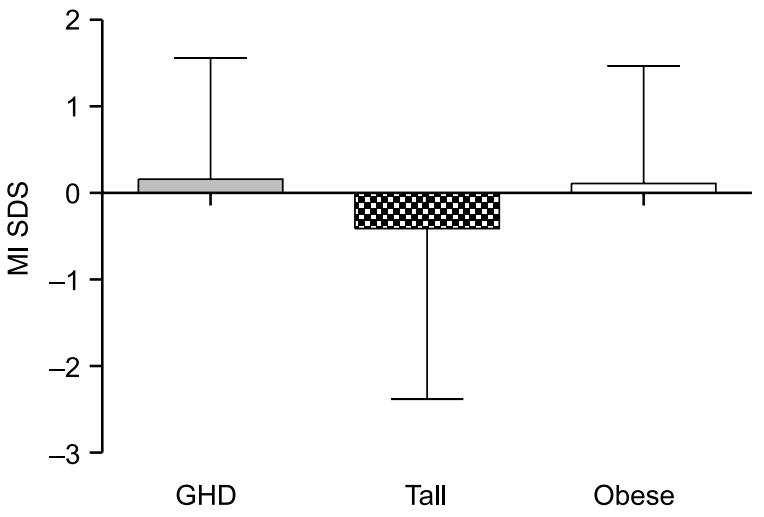

Figure 1 Metacarpal index SDS in growth hormone-deficient (GHD), tall and obese children.

relative gain between the two groups, suggesting no dosage effect of GH. No difference was found when MI SDS was compared with those of the groups of tall and obese children (Fig. 1).

Outer and inner diameters were similar in the two groups at baseline and at final height (Table 4). Total, cortical and medullary CSA were also similar at baseline, while, at final height, the medullary CSA area was significantly larger in group 2 . The percentage changes from baseline to final height (group 1 vs group 2) were as follows: $46.8 \%$ vs $70.9 \%$ (total CSA; NS), $10 \%$ vs $119 \%$ (medullary CSA; $P=0.002$ ) and 61.7 vs $68.4 \%$ (cortical CSA; NS).

\section{Bone strength}

BBRI was similar in the two groups at the beginning and at the end of the study; however, BBRI increased significantly more in group 2 than in group $1(P<0.05)$. The percentage changes from baseline to final height (group 1 vs group 2) were $91 \%$ vs $138 \%$ (NS).

\section{Discussion}

The major finding of this study is that higher doses of GH significantly improve adult stature in GHD children, by stimulating better bone growth in length and diameter and by inducing minor but advantageous changes in bone geometry. The greater height gain by the children receiving the higher $\mathrm{GH}$ dosage agrees with our previous experience in a smaller group of children (6), emphasizing once again the appropriateness of the dosage of $0.3 \mathrm{mg} / \mathrm{kg}$ per week, as also recently recommended by the GH Research Society (16). Children grow because their bones become progressively longer and larger, a process which is under the influence of genetic, environmental and nutritional factors, as well as hormones, such as thyroid hormones, sex hormones, cortisol, GH and IGF-I. Thus, we wished to determine whether a higher dose of $\mathrm{GH}$, besides making the bone grow faster, would also influence its geometry and therefore its resistance to fracture. Moreover, GH and IGF-I influence not only the bone growth but also its mineralization. Evaluation of bone mineral density by bone densitometry (DXA), a technique not comparable with the one used in our study, showed a lower degree of mineralization in GHD children, which normalized after treatment $(17,18)$ and a higher degree of mineralization in acromegaly $(19,20)$. Furthermore, local overexpression of IGF-I has been shown to increase trabecular bone formation and osteoblastic cell proliferation in unloaded rats (21). At the higher doses employed in this study, however, GH seems to have mainly a permissive role in mineralization, since in a previous study we could not find any difference in the bone mineral density of the radius and of the metacarpal bone in two groups of GHD children similarly treated (22).

In this study, cortical thickness was lower in the group treated with the higher dosage before starting treatment with $\mathrm{GH}$ and at final height as well (Table 2). Since no statistical difference in the relative MI SDS gain (Table 3) was observed, we feel that differences in MI SDS between groups might be explained entirely on a genetic basis without GH interference.

Nevertheless, we observed some differences, although not all statistically significant, in bone geometry between the two groups which could be attributed to the $\mathrm{GH}$ action. In fact, the children treated with higher doses tended to have larger bones at final height, as shown by the greater outer diameter and greater total CSA. Of interest is also the fact that they showed a similar cortical CSA to the other group, together with a significant enlargement of the medullary CSA $(P<0.05)$, indicating that the bone in these children was further placed from the neutral axis. This is a favorable situation since the periosteal apposition confers more strength in bending than bone deposited by endocortical apposition nearer to the

Table 4 Outer (D) and inner (d) diameter and total CSA, medullary CSA and cortical CSA and BBRI at baseline (B) and at final height (f).

\begin{tabular}{lcccccccc}
\hline & $\boldsymbol{n}$ & $\mathbf{D}(\mathrm{cm})$ & $\mathbf{d}(\mathrm{cm})$ & \multicolumn{1}{c}{ Total CSA $\left(\mathrm{cm}^{2}\right)$} & Medullary CSA $\left(\mathrm{cm}^{2}\right)$ & Cortical CSA $\left(\mathrm{cm}^{2}\right)$ & $\mathbf{B B R I}\left(\mathrm{cm}^{3}\right)$ & $\mathbf{B B R I}$ gain $\left(\mathrm{cm}^{3}\right)$ \\
\hline Group 1 (b) & 38 & $8.45 \pm 1.52$ & $4.06 \pm 0.56$ & $57.82 \pm 21.97$ & $13.18 \pm 3.88$ & $44.63 \pm 20.32$ & $6.64 \pm 3.98$ & \\
Group 1 (f) & 38 & $9.93 \pm 1.44$ & $4.19 \pm 0.9$ & $78.92 \pm 24.8$ & $14.45 \pm 6.03$ & $64.46 \pm 23.74$ & $10.02 \pm 5.37$ & $3.33 \pm 5.06$ \\
Group 2 (b) & 37 & $8.51 \pm 1.85$ & $4.0 \pm 1.05$ & $59.5 \pm 29.66$ & $13.44 \pm 6.36$ & $46.07 \pm 26.95$ & $5.79 \pm 3.26$ & \\
Group 2 (f) & 37 & $10.12 \pm 1.76$ & $4.65 \pm 1.6$ & $82.69 \pm 27.26$ & $18.94 \pm 12.36^{*}$ & $63.75 \pm 23.4$ & $11.52 \pm 5.49$ & $6.88 \pm 6.65^{\star}$ \\
\hline
\end{tabular}

CSA: cross-sectional area.

${ }^{*} P<0.05$ for the difference between group 1 (f) and Group 2 (f). 
neutral axis of the long bone (23). We confirmed this beneficial effect of higher $\mathrm{GH}$ doses by finding a statistically significant increase in bone strength (BBRI) in this group compared with the other one. Similar findings have been recently reported in a group of children affected with juvenile idiopathic arthritis and treated with $\mathrm{GH}$ for a similar period of time (24). Apart from $\mathrm{GH}$, gender differences within the two groups could have played a role in modulating the changes in bone geometry, since it is known that testosterone mainly stimulates periosteal apposition, while estrogen inhibits periosteal bone apposition and stimulates endocortical bone formation (25). Boys and girls, however, were equally represented in the two groups, and thus gender differences are unlikely to play a role.

In conclusion, higher doses of $\mathrm{GH}$, apart from their effect on adult stature, seem to exert also a positive effect on bone geometry, which would lead to an improved bone stability and thus increased resistance to fractures. However, further studies are needed to confirm the beneficial effect of higher $\mathrm{GH}$ doses on adult stature and bone strength.

\section{References}

1 van der Eerden BC, Karperien M \& Wit JM. Systemic and local regulation of the growth plate. Endocrine Reviews 200324 $782-801$

2 Isaksson OGP, Lindahl A, Nilsson A \& Isgaard J. Mechanism of the stimulatory effect of growth hormone on longitudinal bone growth. Endocrine Reviews 19878 426-438.

3 Brixen K, Hansen TB, Hauge E, Vahl N, Jorgensen JO, Christiansen JS, Mosekilde L, Hagen C \& Melsen F. Growth hormone treatment in adults with adult-onset growth hormone deficiency increases iliac crest trabecular bone turnover: a 1-year, double-blind, randomized, placebo-controlled study. Journal of Bone and Mineral Research 200015 293-300.

4 Ueland T, Bollerslev J, Flyvbjerg A, Hansen TB, Vahl N \& Mosekilde L. Effects of 12 months of $\mathrm{GH}$ treatment on cortical and trabecular bone content of IGFs and OPG in adults with acquired GH deficiency: a double-blind, randomized, placebocontrolled study. Journal of Clinical Endocrinology and Metabolism 200287 2760-2763.

5 Baroncelli GI, Bertelloni S, Sodini F \& Saggese G. Longitudinal changes of lumbar bone mineral density (BMD) in patients with $\mathrm{GH}$ deficiency after discontinuation of treatment at final height; timing and peak values for lumbar BMD. Clinical Endocrinology $200460175-184$

6 Radetti G, Buzi F, Paganini C, Pilotta A \& Felappi B. Treatment of GH-deficient children with two different GH doses: effect on final height and cost-benefit implications. European Journal of Endocrinology 2003148 515-518.

7 Zhang XZ, Kalu DN, Erbas B, Hopper JL \& Seeman E. The effect of gonadectomy on bone size, mass and volumetric density in growing rats may be gender-site-, and growth hormone-dependent. Journal of Bone and Mineral Research 199914 802-809.

8 Yeh JK, Chen M-M \& Aloia JF. Ovariectomy-induced high turnover in cortical bone is dependent on pituitary hormone in rats. Bone $199618443-450$.

9 MacKelvie KJ, Petit MA, Khan KM, Beck TJ \& McKay HA. Bone mass and structure are enhanced following a 2-year randomized controlled trial of exercise in prepubertal boys. Bone 200434 $755-764$.
10 Halloran BP, Bikle DD, Harris J, Autry CP, Currier PA, Tanner S, Patterson-Buckendahl P \& Morey-Holton E. Skeletal unloading induces selective resistance to the anabolic actions of growth hormone on bone. Journal of Bone and Mineral Research 199510 $1168-1176$.

11 Tanner JM \& Whitehouse RH. Clinical longitudinal standards for height, weight, height velocity, weight velocity, and stages of puberty. Archives of Disease in Children 197651 170-179.

12 Rolland-Cachera MF, Cole TJ, Sempé M, Tichet J, Rossignol C \& Charraud A. Body mass index variations: centile from birth to 87 years. European Journal of Clinical Nutrition 199145 13-21.

13 Greulich WW \& Pyle SL. Radiographic Atlas of Skeletal Development of the Hand and Wrist, 2nd edn. Stanford, CA: Stanford University Press, 1969.

14 Zamberlan N, Radetti G, Paganini C, Gatti D, Rossigni M, Braga V \& Adami S. Evaluation of cortical thickness and bone density by roentgen microdensitometry in growing males and females. European Journal of Pediatrics 1996155 377-382.

15 Kerr D, Morton A, Dick I \& Prince R. Exercise effects on bone mass in postmenopausal women are site-specific and load-dependent. Journal of Bone and Mineral Research 199611 218-225.

16 Growth Hormone Research Society. Consensus guidelines for the diagnosis and treatment of growth hormone $(\mathrm{GH})$ deficiency in childhood and adolescence: summary statement of the GH Research Society. Journal of Clinical Endocrinology and Metabolism 200085 3990-3993.

17 van der Sluis IM, Boot AM, Hop WC, De Rijke YB, Krenning EP \& de Muinck Keizer-Schrama SM. Long-term effects of growth hormone therapy on bone mineral density, body composition, and serum lipid levels in growth hormone deficient children: a 6-year follow-up study. Hormone Research 200258 207-214.

18 Saggese G, Baroncelli GI, Bertelloni S \& Barsanti S. The effect of long-term growth hormone (GH) treatment on bone mineral density in children with GH deficiency. Role of GH in the attainment of peak bone mass. Journal of Clinical Endocrinology and Metabolism $1996813077-3083$.

19 Andreassen TT \& Oxlund H. The effects of growth hormone on cortical and cancellous bone. Journal of Musculoskeletal and Neuronal Interaction 20012 49-58.

20 Scillitani A, Battista C, Chiodini I, Carnevale V, Fusilli S, Ciccarelli E, Terzolo M, Oppizzi G, Arosio M, Gasperi M, Arnaldi G, Colao A, Baldelli R, Ghiggi MR, Gaia D, Di Somma C, Trischitta V \& Liuzzi A. Bone mineral density in acromegaly: the effect of gender, disease activity and gonadal status. Clinical Endocrinology $2003 \mathbf{5 8} 725-731$.

21 Machwate M, Zerath E, Holy X, Pastoureau P \& Marie PJ. Insulinlike growth factor-I increases trabecular bone formation and osteoblastic cell proliferation in unloaded rats. Endocrinology 1994134 1031-1038.

22 Radetti G, Buzi F, Paganini C, Martelli C \& Adami S. A four year dose-response study of recombinant human growth hormone treatment of growth hormone deficient children: effects on growth, bone growth and bone mineralization. European Journal of Endocrinology 2000142 42-46.

23 Turner $\mathrm{CH} \&$ Burr DB. Basic biomechanical measurements of bone: a tutorial. Bone 199314 595-608.

24 Bechtold S, Ripperger P, Bonfig W, Pozza RD, Haefner R \& Schwarz HP. Growth hormone changes bone geometry and body composition in patients with juvenile idiopathic arthritis requiring glucocorticoid treatment: a controlled study using peripheral quantitative computed tomography. Journal of Clinical Endocrinology and Metabolism $2005903168-3173$.

25 Seeman E. An exercise in geometry. Journal of Bone and Mineral Research $200217373-380$.

Received 1 September 2005

Accepted 22 December 2005 